There will be enough only if there is a marked improvement in present conditions of pay and terms of service. The encouraging words in the report are no substitute.

The Government has backed the programme with $£ 40$ million additional capital and revenue resources over the period 1971-3. But even if growth continues for the next decade at the maximum rate envisaged by the Government there will be too few training places and homes for the mentally handicapped well into the 1980s. The report estimates that 36,800 residential places are needed for England and Wales; there are fewer than 5,000 at present. Adult day training centres should be able to cope with 72,500 patients; fewer than 25,000 places are available. Why are there so few places? The 1959 Mental Health Act laid a statutory duty on local authorities to provide a full range of community services for the mentally handicapped, including residential accommodation. Yet at the end of 1969 less than a quarter of the local authorities in England and Wales had provided homes of this kind for children and adults. Conditions for the mentally handicapped have improved in the last two or three years, and this new programme will lead to further improvements. But while the level of public interest and concern is low, and while some local authorities seem to "keep the rates down" by spending the minimum, there will still be parts of the country where little is done. Surely any national plan for better services should include some means of ensuring that the local authorities carry it out?

'Department of Health and Social Security. Better Services for the Mentally Handicapped, London, H.M.S.O., 1971. Price 45p.

\section{Non-bacterial Thrombotic Endocarditis}

Sterile vegetations are found on the heart valves in rheumatic carditis and rarely in systemic lupus erythematosus. They consist of platelets and fibrin and are deposited on the surface of an acutely inflamed valve. But sterile vegetations are sometimes also found on valves that are not grossly diseased. This condition is called non-bacterial thrombotic endocarditis, and it affects the mitral and aortic valves predominantly. At the most the changes are confined to a slight degeneration of the collagen framework of the valve. ${ }^{1}$

Non-bacterial thrombotic endocarditis was for long dismissed as a terminal phenomenon of little clinical importance. But in a series of 78 cases R. A. Macdonald and S. L. Robbins found 11 instances of systemic embolism arising from the affected valve, and this either caused or contributed to the patient's death. ${ }^{2}$ Furthermore, these embolic episodes were sometimes the first indication of a systemic illness, and the endocarditis could not be regarded as a terminal event. Over a third of the patients had widespread cancer, and in most of the remainder death was due to heart failure or vascular thrombotic disease.

There seems to be an association between non-bacterial thrombotic endocarditis and cancer. ${ }^{34}$ Thus W. E. Barry and D. Scarpelli found metastatic carcinoma in 12 of their 21 cases, while two others died of leukaemia. ${ }^{5}$ Of the 16 cases collected by R. F. Rohner and his colleagues ten had disseminated cancer, and of these, seven were mucussecreting adenocarcinomata of the stomach, lung, colon, and pancreas. These mucoid cancers were associated with multi- ple large vegetations. ${ }^{6} \mathrm{M}$. RayChaudhuri has recently described four further cases occurring in association with mucus-secreting adenocarcinomata, two bronchial in origin and the others gastric and pancreatic. ${ }^{7}$ In all the cases there were multiple systemic infarcts and also widespread venous thrombosis. The mitral valves were alone affected, and the cusps showed mild degenerative changes in the collagen framework.

The aetiology of non-bacterial thrombotic endocarditis is obscure and its relation to disseminated cancer is not understood. It has been suggested that there is an increased tendency for the blood to clot owing to a possible alteration in the levels of various clotting factors or to the liberation of a mucin-like substance which accelerates the clotting mechanism, but no single finding has been substantiated. Migratory thrombophlebitis is often present as well, ${ }^{6}$ and this adds weight to the possibility that the blood is hypercoagulable. The condition is in fact an uncommon complication even of mucus-secreting adenocarcinomata, and RayChaudhuri found it in only four of a series of 232 cases. $^{7}$ Whatever the aetiology of non-bacterial thrombotic endocarditis, it is clearly of clinical importance and may lead to systemic embolism and infarction.

Eritish Medical fournal, 1967, 3, 812.

- Macdonald, R. A., and Robbins, S. L., Annals of Internal Medicine, 1957, 46, 255.

${ }^{3}$ Smith, J. P., and Yates, P. O., fournal of Pathology and Bacteriology, 1955, 70, 111 .

- Lafier, C. J., and Hinerman, D. L., Cancer, (Philadelphia), 1961, 14, 944.

Barry, W. E., and Scarpelli, D., Archives of Internal Medicine, 1962, 109, 151.

Rohner, R. F., Prior, J. T., and Sipple, J. H., Cancer, (Philadelphia), $1966,19,1805$.

RayChaudhuri, M., British Fournal of Diseases of the Chest, 1971, 65, 98.

\section{Ward Design and Cross- infection}

Infection from patient to patient by staphylococci involves an ever-present threat of sepsis, particularly in surgical wards, and has been extensively studied in Great Britain for some time past. The effect of subdivision has naturally attracted most attention, and an extreme example of this, an infectious diseases ward consisting entirely of single rooms opening on a veranda, was found by $M$. T. Parker and his colleagues ${ }^{1}$ to approach the ideal. Very little exchange of staphylococci between patients occurred. This arrangement is almost impracticable in general hospital wards, and the tendency there has been towards subdivision of most of the accommodation into rooms containing four beds.

A somewhat belated report ${ }^{2}$ (this study was carried out in 1965-6) on conditions in such wards in the Queen Elizabeth II Hospital, Welwyn Garden City, has recently appeared. Here the four-bed rooms are separated from a corridor and thus from the rest of the ward only by a wall $3 \mathrm{ft} .(1 \mathrm{~m})$ high. The usual methods of air sampling and of weekly nasal swabbing of all patients and staff were employed, together with phage typing and antibiotic sensitivity determinations of all strains isolated. Advanced mathematical procedures and a computer were used to analyse the results. Not only did nasal colonization, including that by antibioticresistant strains, increase for five weeks after admission, but evidence was obtained that the source was almost as likely to 
be a patient in a distant part of the ward as one in the same four-bed bay. In fact this kind of partial subdivision "is without effect on the spread of infection". No one: familiar with the facility with which air-borne particles circulate will be surprised at this finding in a ward so constructed.

A similar study ${ }^{3}$ published some years earlier was made in a thoracic surgical ward in which four-bed rooms, four single rooms, and a 10-bed room were connected by a long L-shaped corridor. The four-bed rooms were totally enclosed, but the doors to them were usually open. Here nasal carriage actually diminished after admission, but this may have been because patients received generous doses of penicillin as operation cover. Nevertheless, infections were acquired from patients in other rooms nearly as frequently as from those in the same room.

It seems evident that these bacterial migrations are likely to be prevented only by controlling air flow, and there have been several studies of the effects of this, with far from consistent results. In one of these ${ }^{4}$ part of a surgical ward to which uninfected patients were initially admitted was shut off from the rest and supplied with positive pressure ventilation. It seems from one Figure in this paper that nasal acquisition of staphylococci in this inner ward was considerably less than in the outer, but according to the authors "mechanical ventilation did not lead to any significant reduction in the degree of contamination of the air or in the rate of nasal acquisition of Staphylococcus aureus." In a later extension of this study both parts of the ward were mechanically ventilated, but the appearance of a type 84/85 multi-resistant staphylococcus with an exceptional capacity for spread led to the colonization of so many patients that its source in any one of them was untraceable. In another study 5 in an experimental ward filtered air was supplied to patients' rooms and to three other areas at different rates, but information is not given about the direction of any air flow between them. The rate of nasal infection was somewhat lower than in two other wards not so ventilated, but this was true of only the first two weeks after admission, did not apply to tetracycline-resistant strains, and did not lead to any diminution in staphylococcal sepsis.

The most encouraging report on a system of this kind is one from Aberdeen ${ }^{6}$ which appeared a few months ago. The new ward there is of the "race-track" type, consisting of numerous completely enclosed single rooms and rooms containing four or five beds, opening on an inner corridor, which itself encloses a "service core". Air is supplied under positive pressure only to the patients' rooms, and passes thence centripetally to exhaust through the service core. Smoke tests consistently showed that the direction of flow was from the patients' rooms even when doors were open. Removal of patients to this ward from an old one of the "Nightingale" type, although the patients transferred included carriers of an endemic strain of staphylococcus which had been a serious cause of wound infection for two years, was followed not only by diminution in the rate of nasal infection, but by a great reduction in staphylococcal air counts and a $72 \%$ reduction in the frequency of exogenous wound infection. These achievements strongly suggest that a properly controlled system of ventilation in a subdivided ward can have the good effect which is theoretically to be expected from it.

\footnotetext{
' Parker, M. T., John, M., Emond, R. T. D., and Machacek, K. A., British Medical fournal, 1965, 1, 1101 .

2 Lidwell, O. M., Davies, J., Payne, R. W., Newman, P., and Williams, R. E. O., Fournal of Hygiene, 1971, 69, 113.

${ }^{3}$ Lidwell, O. M., Polakoff, S., Jevons, M. P., and Parker, M. T., fournal of Hygiene, 1966, 64, 321 .
}

${ }^{4}$ Lidwell, O. M., et al., fournal of Hygiene, 1970, 68, 417.

Whyte, W., Howie, J. G. R., and Eakin, J. E., Fournal of Medical Microbiology, 1969, 2, 335.

Smylie, H. G., Davidson, A. I. G., Macdonald, A., and Smith, G., British Medical fournal, 1971, 1, 67.

\section{Worcestershire Sauce and the Kidneys}

A little of what you fancy may do you good, but an excess may have the opposite effect. Among the contents of the kitchen shelf there are several which, if ingested in massive quantities over a long period of time, can lead to damage to the kidneys. These include milk and alkalis, ${ }^{1}$ vitamin $\mathrm{D},{ }^{2}$ analgesics, ${ }^{3}$ and purgatives. ${ }^{4} \mathrm{~A}$ less familiar possible nephrotoxin is Worcestershire sauce. In 1956 A. H. Douthwaite ${ }^{5}$ described the case of a 59-year-old man with chronic renal failure who habitually took half to one bottle of Worcestershire sauce each day. His blood pressure was raised, his urine contained protein and casts, the blood urea ranged from 76 to $110 \mathrm{mg} / 100 \mathrm{ml}$, and his urea clearance was $18 \%$ of normal. A month after ceasing to take Worcestershire sauce he had lost his symptoms and gained weight, his urine was free from protein and casts, and his blood pressure and blood urea had returned to normal.

More recently K. J. Murphy ${ }^{7}$ has reported five patients with renal disease for which none of the usual causes was apparent but whose taste for Worcestershire sauce had led to excessive intake-in one case by the "glassful". Three of them had bilateral renal calculi and a generalized aminoaciduria; one of the others had malignant hypertension and end-stage renal failure; and the remaining patient had moderate impairment of renal function, which seemed to improve after he stopped taking Worcestershire sauce. Proteinuria was present in three of the patients, and urinary acidification tests with ammonium chloride gave an abnormal result in all, usually a low titratable acidity and phosphate excretion but a normal ability to lower $\mathrm{pH}$. Renal biospy obtained in one of the patients without stones showed that some of the glomeruli were normal but that others were completely sclerosed or had organized crescents. There was a little diffuse interstitial fibrosis.

Worcestershire sauce contains acetic acid, garlic, black pepper, and a variety of other spices. Which, if any, of these may have a toxic effect on the kidneys is uncertain. The evidence against Worcestershire sauce is not yet strong enough to incriminate it, but it is sufficiently suggestive to make it worth asking patients with unexplained renal impairment or calculi about the condiments they take. Even if further cases should substantiate a connexion, Worcestershire-sauce nephropathy is unlikely to turn out to be a common disease, since presumably the population addicted to these enormous quantities is not large. Nevertheless, the discovery of another potentially reversible cause of renal failure is worth noting.

\footnotetext{
1 Burnett, C., Commons, R., Albright, F., and Howard, J., New England Fournal of Medicine, 1949, 240, 787.

${ }^{2}$ Anning, S. T., Dawson, J., Dolby, D. E., and Ingram, J. T., Quarterly Fournal of Medicine, 1948, 17, 203.

${ }^{3}$ Spuhler, O., and Zollinger, H. O., Zeitschrift für klinische Medizin, 1953,

151, 1. W. B., and Relman, A. S., fournal of Clinical Investigation,
4 $1953,32,258$.

5 Douthwaite, A. H., British Medical fournal, 1956, 2, 958.

'Murphy, K. J., Lancet, 1967, 2, 401.

7 Murphy, K. J., Medical fournal of Australia, 1971, 1, 1119
} 